\title{
IMPLEMENTING COLLABORATIVE PROJECTS IN THE TECHNICAL WRITING CLASSROOM
}

\author{
ANNE PARKER \\ UNIVERSITY OF MANITOBA
}

\begin{abstract}
Scholars in the field of technical communication have frequently remarked on the collaborative nature of many engineering projects, and they have also extolled the merit of introducing this kind of writing into the technical writing classroom. But the problem of implementing collaborative projects in the classroom has not yet been satisfactorily addressed, nor have many solutions to the problem been workable in the context of the classroom. This paper, after defining what collaboration means, will outline some of the problems and some of the solutions. Later in the paper, I will briefly discuss two particular collaborative projects, writing an abstract and preparing an oral report.
\end{abstract}

\section{INTRODUCTION:}

More and more, collaborative writing has been trumpeted in the literature, not just as a good idea whose time has come, but also as "sound pedagogy" (Couture and Rymer, 76; Scott, 138, 142). We are told that group projects are commonplace on the job (Tryzna and Batschelet, 369; Morgan et al, 20). We are also told that, as educators, we should be introducing such projects into the technical writing classroom and thereby helping our students prepare themselves for the workplace.

But how do we incorporate collaborative projects into the technical writing classroom? Just how do we go about implementing this good idea--given our time constraints, our teaching loads and our already packed curriculum? 
Many technical writing instructors are justifiably wary of introducing collaborative projects in the first place, and not always because of the questions cited above. For one thing, there are problems with classroom management and assessment (Beard et al, 30). For another, there is the problem of defining what input, if any, the instructor should have in any collaborative group. Is the instructor, for example, to be similar to a boss and be interested only in the final product, or is the instructor to be more involved in the group's collaborative process? If instructors are to play a more active role, their ability to recognize potential problems in a collaborative group becomes as critical as their ability to know when to interfere and when to stay neutral (Scott, 140). And then there is the additional problem of the differences between instructors, their interests and abilities, not to mention the diversity of the students themselves. For these reasons, then, instructors may avoid collaborative projects altogether, or introduce them only to abandon them later (Beard et al, 30).

Certainly there are problems associated with collaborative projects, some of them critical to classroom teaching and others inherent to the collaborative effort itself. This paper will show how collaborative projects can be implemented in the technical writing classroom.

\section{DEFINING COLLABORATION:}

In order for collaborative projects to work at all in the classroom, everyone, including the instructor, needs to have a clear idea of what collaboration means; that is, everyone must have a clear idea as to what is expected of him/her in a collaborative setting. Without this, students may summarily dismiss collaboration as a "bad idea" or, worse, decide to do as little of the work as possible. Students need to feel, and to be, involved; they need to feel responsibility for, and pride in, the project; they must recognize that they have a vested interest in the project. Defining collaboration so that they will indeed respond in this way is an important first step to introducing collaborative projects into the technical writing classroom. 
However, neither the kind of collaboration nor the frequency with which people on the job can expect to collaborate are clearly defined. Even defining collaboration can become tricky, although the most widely accepted definition is that more than one person works on a project in some way. Accordingly, different scenarios are possible; for example, a subordinate writes the draft and the boss signs it; or several people "co-author" a document; or one person alone writes a document and then colleagues revise it; or the writer solicits input from colleagues through discussions, revision or proofing the final product.

But students are not yet "on-the-job." In a classroom setting, students "must produce as a team without the authority or reward system of a job" (Goldstein and Malone, 114). As instructors, we can hardly fire a recalcitrant student who is not contributing or doing an equal share of the work. And we certainly cannot throw someone out of the class because he or she is content to just "pass" and the group wants an "A." As Forman and Katsky point out, "students' motivation for conducting a project may vary" (26).

So, what instructors need to emphasize to students is that collaboration involves many kinds of sharing, to borrow Morgan et al's term (22), not the least of which is sharing the workload. For students to share the workload, however, the collaborative project should be one which is both complex enough and, at the same time, straightforward enough to warrant more than one point of view; in other words, there must be some scope to the project. To work, the collaborative project should be one which demands that more than one person do the work because, otherwise, the work might not get done within the time limit (Allen et al, 86). To work, the collaborative project should be one which lends itself to many people's contributing to it, one that, if done by a single person acting alone, would not lead to as good a document as a shared one would (Morgan et al, 20-21). Clearly, if it is not complex enough to warrant a group effort, then the workload cannot with reason be shared.

It is the sharing which is so crucial, and time and again scholars in the field of collaborative writing stress the importance of this sharing. It takes many forms: not just shared workload, but also shared 
responsibility, shared decision-making, shared planning (for every aspect of the document) and shared revision (Allen et al, 80, 70, 84, 77; Morgan et al 22).

The bottom line is, and must be, that each student has a stake in the project. Whatever the team produces is each student's responsibility.

To ensure that groups are successful, it is important to stress that the interaction among and between all the group's members must be substantial. They must be prepared to discuss, and even to argue, openly and freely. Their goal as a group is to reach a consensus, to reach decisions they all can live with (Morgan et al, 21; Beard et al, 40). Ultimately, the group should reach decisions and create documents which are "better" than they would have produced as individuals. At least, that's one of the goals of collaborative writing. But many problems, particularly in a technical writing classroom, can interfere and even prevent a group's reaching that goal. Instructors need to be aware of what the problems are likely to be and take measures to solve them--quickly.

\section{PROBLEMS WITH IMPLEMENTING COLLABORATTVE PROJECTS IN THE TECHNICAL WRITING CLASSROOM:}

Several problems can be identified as the most troublesome, at least from an instructor's point of view: defining what the roles of each group member will be and what role the instructor will play in the group's dynamic; deciding how large a collaborative group should be; determining how students can be encouraged, and motivated, to get involved in the collaborative project, especially when their skills and levels of commitment can be so various and uneven. Another problem is coping with conflict within a collaborative group. Finally, yet another problem concerns classroom management and student assessment: how do you assess students involved in collaboration and how do you handle a class comprised of several groups of students, each working on their own group project? 
(1) Collaborative Groups in the Classroom:

As previously stated, students are not "on-the-job," so their motivation for investing in both the project and the group is not always high. Certainly, they want to achieve a good mark in the course, but many feel they could do that far more easily by themselves, without having to worry about what their classmates are (or are not) doing. Instructors, then, will have to stress that it is the group which will be the means of accomplishing the students' goals in the course (Morgan et al, 23), and so each student must accept responsibility for the success or the failure of the group itself (24).

Because of this emphasis on the group's performance, instructors cannot interfere in what the group does over the course of the project. Rather, an instructor must be viewed as someone to turn to for advice and help only when needed. Encouraging students to keep a journal of impressions, thoughts and feelings as well as an engineering log of the project, including detailed notes of all the meetings and discussions (Morgan et al, 23), are two ways to ensure that an instructor can be kept informed of any difficulties. Relying on students to keep a journal which will, in turn, keep an instructor informed doesn't always work, whereas a log is usually detailed enough to suggest problems. On the other hand, as a personal record, a journal has to be treated confidentially, like a private consultation between a student and the instructor; it most certainly cannot be included in the grading process.

What the journal reveals are some of the issues which plague collaborative projects: lack of commitment and imbalance in the workload, two of the most common complaints which instructors can expect to hear. Some team members may skip meetings or consistently come late, so that their input into the project is almost negligible. Or some team members cannot get their drafts in on time and frequently delay the work of others. All too often, one or two students seem to do all the work while everyone gets equal credit; after all, in a collaborative effort, they will receive the same reward for the project.

Usually, the students who feel they do the lion's share will be those "better" students who are more motivated, eager as they are to do well 
and get a good mark. Not only are they more capable of doing well, but also their team mates are only too willing to let them do most of the work. Alternatively, some groups suffer from one person's dominating the entire project, from meetings, to decisions, to the final report itself.

That is why the size of the group should be carefully considered. Any more than five members will make the group too unwieldy; little will be accomplished. Any less than three will defeat the purpose of true collaboration since the workload will not be significantly reduced and neither will there be the value of several points of view. Morgan et al suggest that a group of three to four is workable (22); Scott uses groups of four or five (138). In my experience, either four or five will make a workable group.

Establishing these groups can be difficult, especially if the collaborative project is a major component in the course. Student timetables can create real problems for the students since they may find it difficult to find times to get together. For this reason, Morgan et al try to group students according to their timetables (22). Grouping students according to their level of writing ability is another way.

Other problems can occur, though, to complicate the instructor's establishing groups. For example, students withdraw from a course, or miss classes, or just don't care enough to be responsible. Starting the collaborative process too early may mean students are too uncomfortable with each other, too hesitant about what you are asking them to do, particularly in what to them are unfamiliar circumstances, and they may not respond well. Indeed, developing a sense of "groupness" can take up to half the project (Morgan et al, 22) or, in my case, half the course.

Establishing specific roles each can play in the group helps to alleviate these problems, since, once students know what they are to do, they can then begin work. These roles should reflect the major components of any project, such as graphics, style and technical content. Whoever is responsible for the graphics, for example, would not simply choose them or draw them. This person could ask that everyone look for illustrations for the report, and then be the one responsible for 
integrating them into the text of the document. So, too, with the person responsible for style. He or she would not do all the writing or editing, but would carefully check each draft for errors and then ask each writer to revise that section. As well, the group as a whole would be making choices about all these different elements.

Finally, each group needs a co-ordinator, someone who will set up the meetings and agendas, and ensure that things are kept on track and that deadlines are met. Often, the "better" students assume this role since it gives them some measure of control. But this person is not like a "boss," the final authority on a project. The role of the co-ordinator is an administrative one only.

Nevertheless, in spite of all the precautions and the careful planning, conflict can, and does, occur. Rarely does a group "get on swimmingly," without incident. So, everyone needs to be prepared in advance for what could otherwise seriously harm the group and the project.

\section{(2) Coping With Conflict in a Collaborative Group:}

Most students, like most people, try very hard to avoid conflict simply because they see conflict as disruptive and difficult to control (Forman and Katsky, 25). Perhaps even more important, however, is that most people are simply not used to being open and honest and fighting "above the belt" (Lay, 22). Certainly, coping with conflict is an area which is seldom touched on by most courses and, indeed, few of us in the technical writing field actually teach it.

Nevertheless, in spite of all efforts to avoid it, some conflict will probably occur in most groups. As instructors, once we are aware there is a problem, we must be prepared to deal with it promptly and efficiently and fairly, usually by talking to team members (either separately or as a group), or by suggesting ways to handle the problem. Sometimes, for example, working in sub-groups of two or three works well for some groups. Other times, simply changing the location of a meeting from a classroom to someone's apartment or home will relieve some of the tensions in a group. To be fair, and to be seen to be fair, an instructor must listen carefully to all sides and attempt to placate each side. Also, knowing 
what provokes conflict in the first place can frequently allow him/her to ameliorate potentially disruptive situations.

A common complaint, for example, is that "students disagree over how much work each member is or should be doing" (Morgan et al, 23), and this disagreement may or may not be based on what is actually the case. Another area of disagreement concerns the level of commitment each member feels toward the project--and, by implication, toward the team. Ultimately, there will be resentment toward the student who seems to be taking over and making all the decisions (Morgan et al, 23; Forman and Katsky, 25).

In my course, I have also found that conflict can arise because of sexism and chauvinism, something Lay discusses in her excellent article on gender (5). In a group where there are both males and females, I have found that some males will actually try to dominate the females in the decision-making process.

In one group, for instance, one young man relegated his female associate to such tasks as typing out the final project--and even writing large portions of it. Needless to say, this created resentment on her part. In yet another group, the males heartily resented having a woman as the group's co-ordinator, a role which simply translated into arranging agendas and meetings. But their way of controlling the group was to declare she knew nothing about the topic, which happened to be an innovative vehicle design, and to insist they knew better. In both instances, the instructor was forced to intervene.

These examples underline how serious conflict can be since it will adversely affect both the cohesiveness and the functioning of what should be a collaborative group. Often, it results because students fail to acknowledge the group as the means of achieving their goals (Morgan et al, 23). Indeed, these students will insist that they work better alone and wish the project were an individual effort. Coupled with this is their failure to see the group as an interconnected unit (Lay, 19), where each person in each role has a decisive role to play. 
Nevertheless, student groups need to be made aware that conflict is essential to the group process. When different group members hold contradictory views and are willing to express them in a non-threatening way, then conflict can encourage open discussion and the kind of intellectual exchange which is so important to learning. In fact, as Warburton notes, groups should be "suspicious" of decisions which they have reached quickly and easily, with little or no discussion along the way (313). Where there has not been this kind of free exchange, "defective" decision-making can result (Morgan et al, 24).

Therefore, the "bottom line" for effective collaboration must be that students should never try to avoid conflict. Rather, they must learn how to deal with it--and that advice must include instructors.

As instructors, we can unobtrusively monitor groups during class time, and watch especially for members who tend to talk too much or, alternatively, not at all. Watching for involvement on the part of everyone is also important. But watching groups in action can be misleading since some students tend to "perform" for the benefit of the instructor while outside of class they are dull, disinterested or even obstructive. So, your own observations will only give you a rough idea of how well a group interacts or collaborates. A more useful way to monitor their collaboration is to use different assignments as checks, such as confidential reports on the group or the students' journals. Both the collaboration done inside and outside of class should be included in any assessment of a group project.

However, along with the other problems of defining collaboration and motivating students, conflict can really make classroom management and student assessments difficult, to say the least.

\section{(3) Classroom Management and Assessing Students:}

Included under the term "classroom management" are such things as: determining which assignment will be a team assignment; setting up the collaborative student groups; deciding on the topics and whether they should be assigned by the instructor or chosen by the student(s); and, lastly, observing the groups without intervening or interfering with 
their group dynamic when they are in class or when they come for a consultation outside of class.

Related to all these questions of classroom management is the problem of assessing students. Instructors must determine, in advance, whether they will assess the group, the individual or both (Beard et al, 30). For example, if you grade only the group-written product, the report, you will have to ignore individual contributions to the group process (Beard et al, 30). If the grade awarded is a team grade, then teams may see this as offering little inducement to manage their groups well, or to practice group participation skills or to contribute to the best of their abilities (30; Covington, 101). They crave that individual reward for what they do.

To counteract this tendency, you must have an individual grading component for some portion of the assignment which will offset a student's tendency to "lessen" his or her efforts when assigned group work (Beard et al, 41). Also, such an individual grade encourages these students to develop their own writing skills as well as their group skills.

Without this kind of inducement, the students may simply divide the report into convenient sections and then assign each team member to write a particular section. The result, as expected, is a series of "discrete sections," of what are in effect individual writing projects but under one cover (Beard et al, 41; Forman and Katsky, 31). Group editing, along with group management (such as dividing up the tasks), can create real problems for a group made up of what Forman and Katsky call "multiple voices" (30).

My experience would confirm the dual importance of group work and individual contributions to the group project. Unfortunately, though, I learned the hard way; namely, by doing things wrong and then having to correct the situation.

I began the course by assigning a formal, collaborative project to be completed by the end of term. The report itself was to be a wellresearched evaluation of an engineering topic. Other assignments, given throughout the course, were designed to help students complete this 
longer project. These other assignments, some done individually and some done collaboratively, helped me assess the performance both of individual students and of teams. So far, so good. But I then made one mistake after another.

At first, students chose their own topics and submitted a proposal outlining such things as the information available on the topic, the proposed structure of the final written report and a tentative work schedule for the project. I would then approve which proposals the teams would work on; once a proposal had been approved, the writer would become the project leader for that team. All the other proposals would be dropped, and their writers would be assigned to a project team of three students. In a class of 30 students, then, 10 proposals would be approved. I based the decision strictly on how well-written the proposal was, on whether it was an interesting topic with sufficient information available, and on how well-planned the project was.

At first glance, this procedure would seem to be, if not exactly conducive to collaboration, then at least an appropriate and efficient way to select topics and to assign students to teams. But the real problem was that each student had researched a different topic. So, those students whose proposals had not been approved had wasted valuable time researching a different topic altogether to the one they now had to work on. The fact that they could no longer work on a topic of their choice added, in some cases at least, to their sense of disgruntlement. To add to the problem, some project leaders tended to view the report as "their idea, their project," and many a project leader became autocratic, if not downright nasty, when it came to any changes proposed by other group members.

Assessing the final written report also became increasingly difficult-even though my intentions were good. I wanted to reward the individual for his/her work, so half the grade for the report was strictly an individual grade, awarded on the basis of that student's individual section of the final report. The other half was a team grade, awarded on the basis of the document as a whole (but in actual practice it was more an average of all the individual grades). That way, a student who had done very little work on the final project would do poorly on 
the individual component even though the team grade might be adequate.

Such a means of rewarding individual effort sent conflicting messages. Students were to co-operate, certainly, on the final product, but there was a competitive edge to it where one student could get a higher mark than another, just like they did when they worked on a non-collaborative project. As a result, I encountered some real problems in terms of unequal workload, domineering project leaders, imbalances in the level of skills and in the level of commitment. Clearly, the better students--those wanting the " $\mathrm{A}$ " on the individual component-would do more than their share of the work and might well bully the members of their team. What I needed to do, as Beard et al suggest (30), was certainly to reward both group performance and individual participation, but not at the same time and in the same assignment. What I needed to do was reward participation in the group process itself and in the writing process.

Doing so means that instructors who use collaborative projects can accomplish some very important goals. First, we could now concentrate, not just on the product, but also on the process behind it, an area most technical writing classes emphasize. Secondly, all team members would be encouraged to give their best and to learn to develop their communication skills; in other words, there would be a reason, a mark, for students to get involved. Lastly, we would be promoting the kind of fairness students rightly expect (Beard et al, 30). If collaborative projects are seen by many students as "potentially unfair" (Morgan et al, 24), then somehow their individual contributions must be both noticed and rewarded.

In the final analysis, for a group project, the grading system should ensure that all students participate in the group process and the writing process, and whatever reward is given should be perceived to be fair. To that end, students should assume an equal share of the load; for example, each could be responsible for researching and writing a major section of the report or, alternatively, one student may write less of the final product but contribute more to the word processing of the document in all its many drafts. But the bottom line must be that the team receives 
a grade for the final report.

Individual students should receive individual grades for other things, such as their participation in class and in the group. Students also are responsible for writing at least two individual assignments. This latter requirement ensures that shows a student's written performance is evaluated and shows us that a student has in fact developed adequate writing skills.

\section{TWO EXAMPLES OF COLLABORATIVE PROJECTS: THE ABSTRACT AND THE FINAL ORAL REPORT}

Most collaborative projects should start fairly early in the school term, even though not all students will feel particularly comfortable with this arrangement, as indicated earlier. An early start means that teams can begin to develop that sense of "groupness" that Morgan et al speak of (22). I, too, have found that establishing teams early, usually in the first week or two of classes, is best, even though their first collaborative assignment may be some weeks away.

Nevertheless, having students "settle in" first to the rigors of the course is also an advantage, so I have the students begin by writing two individual assignments, a Proposal and a short formal report. That way, I can assess their writing skills, and use that assessment as one basis for assigning students to groups. For example, as much as possible, I try to assign students with weaker writing skills to groups composed of students with stronger writing skills.

Roughly a third of the way through the term, I assign the first collaborative assignment, the abstract, based on Mendelson's exercise (1-10). The abstract assignment fulfills a twofold purpose: the team develops a sense of "groupness" and learns the value of abstracting information. In this assignment, teams choose a technical article of roughly five to six pages and each member prepares an abstract of it in draft form. In the first Abstract class they must look over each individual draft and produce another version of the abstract for the second abstract class. Throughout the process, I try to let groups find the way they 
work best.

But there are three provisos. First, all draft versions of the abstract must be submitted with the assignment; this gives me a "paper trail" that I can use to see both how well they have collaborated and how well they have managed the writing activities. Secondly, teams should revise as a group (rather than as individuals) since I want the team to do the assignment as opposed to the person who is the best writer. Thirdly, students must assume defined roles, such as recorder/secretary for the group, co-ordinator and technical editor.

Each submitted assignment is then given a team grade according to the quality of the finished abstract. But it is also evaluated according to how well each individual component or role has been performed. For example, along with the finished copy of the abstract, teams submit four appendices: the team's revisions to the final abstract; other, individual versions of the abstract which the team has either incorporated into the final version or rejected altogether; the recorder's notes of the group's discussions during all the meetings (in and out of class) devoted to the abstract assignments; and, lastly, a copy of the original article itself. The recorder's notes of the collaboration which has taken place, the writing/editing process and the content of the abstract are all part of the team grade.

Finally, another collaborative assignment is the final oral report, which the students present at the very end of the course; that is, after they have submitted their final written report. In the final oral report, each team member must present an overview of his or her individual section contained in the written document. Additionally, each team member is responsible for a major section of the oral report itself, such as the introduction and conclusion, the summary of the project (including purpose, problem and scope), the summary of the team's collaboration or the evaluation of the project as a project.

This assignment, like the written project, emphasizes the importance of team planning. Teams must organize their presentations as well as their visual aids, tasks which demand extensive practice and collaboration. By this time, though, the teams are well-established, 
and the final oral reports are amazingly good, given the students' relative youth and inexperience.

Individuals can vary widely as to their prowess as speakers, so I evaluate each speaker individually, looking for both content and delivery. Doing so enables me to give each speaker personal feedback on his/her performance and helps the individual to improve as a speaker. But the grade for the assignment is again a team grade. In the final analysis, it is the team's professionalism and its co-ordination of the presentation--such as managing the lights, the visual aids and the question period--and not just their individual speaking skills which will lead to the reward of a better grade.

\section{CONCLUSION:}

Like any "good idea," introducing collaborative projects demands careful planning on the part of the instructor. For example, you will really have to "sell" the notion of group work to some students. Doing that involves a clear focus on group participation as well as individual contributions. To that end, contributions both to the collaborative process and to the final written (or oral) product must be emphasized and acknowledged. Of course, you will still need individual assignments to complement the group assignments, if only to allow you the opportunity to evaluate the progress and ability of each student. And it goes without saying that you will have to be prepared, in each and every class where you focus on group work, and in each and every student consultation.

But the "bottom line" may well be the student feedback which in my experience is generally, though not always, positive. Students tell me that this collaborative project is the best part of the course and, for some, it is the best part of their engineering program since they learn more by doing this kind of project than they could in lectures.

In sum, I have found there are many benefits to introducing collaborative projects into the technical writing classroom, including: 
- collaborative projects more nearly approximate experience in the "world-of-work" (Scott, 142);

- as in any writing class, students learn by their own experience and not just in lectures;

- students learn from each other as peers;

- the finished product tends to be "better," more polished than individual reports have been in the past;

- team work can lead to better and more creative solutions to engineering problems;

- the group itself becomes the means of accomplishing the students' goals in the course (Morgan et al, 23), and students can thereby develop important interpersonal and communication skills essential to their future success, skills they might not otherwise develop in a more conventional classroom.

If, as Couture and Rymer suggest, this is "sound pedagogy" (76), then it is certainly worth trying, especially if it can indeed help students develop and improve their written and oral communication skills.

One last note: When I first introduced collaborative projects, I did so with only my own enthusiasm to carry me through. What I had to learn--and what I did learn--was that, for collaborative projects to work in the technical writing classroom, these problems of defining collaboration, coping with conflict, assessing the students and managing the classroom had to be addressed and solved. Only when both the instructor and the students alike were aware of what collaboration entailed could collaborative projects be successfully implemented in the classroom. 


\section{REFERENCES}

Allen, Nancy, Dianne Atkinson, Meg Morgan, Teresa Moore, and Craig Snow. 1987. "What Experienced Collaborators Say about Collaborative Writing." Iowa State Journal of Business and Technical Communication. 1:2, 70-90.

Beard, John D., Jone Rymer and David L. Williams. 1989. "An Assessment System for Collaborative-Writing Groups: Theory and Emperical Evaluation." Journal of Business and Technical Communication. 3:2 (September), 29-51.

Couture, Barbara and Jone Rymer. 1989. "Interactive Writing on the Job: Definitions and Implications of 'Collaboration."' In Writing in the Business Professions. Ed. Myra Kogen. National Council of Teachers of English. 73-93.

Covington, David H. 1984. "Making Team Projects Work in Technical Communication Courses." The Technical Writing Teacher. 11:2 (Winter), 100-104.

Duin, Ann Hill. 1991. "Computer-Supported Collaborative Writing: The Workplace and the Writing Classroom." Journal of Business and Technical Communication. 5:2 (April),123-150.

Dillon, Linda S. 1985. "Three Approaches to Writing for Group Acceptance." The Technical Writing Teacher. 11:3 (Spring), 186-189.

Flynn, Elizabeth, Gerald Savage, Marsha Penti, Carol Brown and Sarah Watke. 1991. "Gender and Modes of Collaboration in a Chemical Engineering Design Course." Journal of Business and Technical Communication. 5:4 (October), 444-467.

Forman, Janis. 1991. "Novices Work on Group Projects: Problems in Group Writing and in Computer-Supported Group Writing." Journal of Business and Technical Communication. 5:1 (January), 48-75. 
Forman, Janis and Patricia Katsky. 1986. "The Group Report: A Problem in Small Group or Writing Processes?" The Journal of Business Communication. 23:4 (Fall), 23-35.

Goldstein, Jone Rymer and Elizabeth L. Malone. 1984. "Journals on Interpersonal and Group Communication: Facilitating Technical Project Groups." Journal of Technical Writing and Communication. 14:2, 113-131.

Gross, Gerard J. 1981. "Group Projects in the Technical Writing Course." In Courses, Components, and Exercises in Technical Communication. Ed. Dwight Stevenson. National Council of Teachers of English. Urbana: Illinois: 54-64.

Lay, Mary M. 1989. "Interpersonal Conflict in Collaborative Writing: What We Can Learn from Gender Studies." Journal of Business and Technical Communication. 3:2 (September), 5-28.

Mendelson, Michael. 1987. "Teaching the Abstract as an Introduction to Technical Writing." The Technical Writing Teacher. 14:1 (Winter), 1-10.

Morgan, Meg, Nancy Allen, Teresa Moore, Dianne Atkinson, and Craig Snow. 1987. "Collaborative Writing in the Classroom." The Bulletin for the Association for Business Communication. 50:3 (September), 20-26.

Scott, Ann Martin. 1988. "Group Projects in Technical Writing Courses." Technical Writing Teacher. 15:2, 138-142.

Stratton, Charles R. 1989. "Collaborative Writing in the Workplace." IEEE Transactions on Professional Communication PC-32:3, 178-182.

Trzyna, Thomas N. and Margaret W. Batschelet. 1987. Writing for the Technical Professions. Wadsworth Publishing Company. 
Warburton, T.L. 1987. "The ABCs of Group Communication: A Primer for Effective Group Performance." Technical Writing and Communication, 17:3, 303-315.

Dr. Anne Parker teaches first-year engineering students at the University of Manitoba. She has published articles in Technostyle and The Technical Writing Teacher, and is currently working on a manuscript for a technical writing text on the workshop. Her research interests include: collaborative projects in the technical writing classroom; evaluating group projects; the problem-solving approach to technical communication; the workshop as a teaching tool. In 1990, she became the editor of Technostyle. 